\title{
FERMENTATION OF MILK WHEY PERMEATE WITH DIFFERENT DAIRY PROPIONIBACTERIA STRAINS
}

Unigunde ANTONE, Faculty of Food Technology, Latvia University of Life Sciences and Technologies (LLU), Rīgas iela 22, Jelgava, Latvia, unigunde.antone@1lu.lv (corresponding author)

Janis LIEPINS, Institute of Microbiology and Biotechnology, University of Latvia (LU), Jelgavas iela 1, Riga, Latvia, janis.liepins@lu.lv

Jelena ZAGORSKA, Faculty of Food Technology, Latvia University of Life Sciences and Technologies (LLU), Rīgas iela 22, Jelgava, Latvia, jelena.zagorska@.1lu.lv

Ingmars CINKMANIS, Faculty of Food Technology, Latvia University of Life Sciences and Technologies (LLU), Rīgas iela 22, Jelgava, Latvia, ingmars.cinkmanis@1lu.lv

This research was focused on whey ultrafiltration permeate (UF) fermentation by genetically unmodified (wild) organisms. We chose five classical Propionibacterium (Prb) strains that are attributed to the dairy subclass. The optimal temperature for Prb growth is around $28-30^{\circ} \mathrm{C}$, however, for energy saving purposes the aim of this study was to observe the organic acid, especially propionic acid (PA) and biomass production of the chosen Prb (DSM 20273 Acidipropionibacterium acidipropionici $=$ A, DSM 20272 Acidipropionibacterium acidipropionici = B; DSM 4902 Prb. freudenreichii = E; DSM 20535 Acidipropionibacterium jensenii $=\mathrm{J}$; DSM 20276 Acidipropionibacterium thoenii $=\mathrm{T})$ at the room temperature $\left(22 \pm 0.5^{\circ} \mathrm{C}\right)$. As expected, all the strains were able to convert lactose into acid, however, with different efficiency, thus the production of PA by Prb is strain-dependent. The higher productivity of PA was observed in samples with strains T, J, and B in a 26-day period, however, it should be noted that also the strain E showed high efficiency in a shorter (6-day) period. The highest concentration of PA was produced by strain $\mathrm{T}$, and it reached $3.7 \pm 0.13 \mathrm{~g} \mathrm{~L}^{-1}$ within a 26-day period. The concentration of the PA produced depends on the duration of fermentation, and on the proportions of other acids produced as well. An individual strain initially can produce PA more slowly than others, but over time can be effective, which may be related to adaptation to environmental conditions. We also observed the presence of background microflora in whey permeates - most likely lactic acid bacteria. Lactic acid was produced most rapidly and was the most abundant acid produced from whey UF.

\section{Keywords: dairy, Propionibacterium, lactose, whey permeate, fermentation, propionic acid}

\section{INTRODUCTION}

Utilizing waste products that are generated from technological processes is one of the significant problems of producer companies and environment specialists (Piwowarek et al., 2018). Manufacture of cheese and curd produces by-product - whey, which constitutes approximately $85 \%$ of the milk as raw material (Panesar et al., 2007). Whey is high in organic matters and therefore its potential for environmental pollution is high (Morales et al., 2006). Often whey is not processed but sold further to biogas plants as raw material at a low price. Many dairy companies find it difficult to process whey and lactose. Currently many dairy companies in Latvia seek options for byproduct conversion into new products. Microbial bioconversion might be one of the feasible options for whey valorization. Whey is a valuable resource - it retains about $55 \%$ of total milk nutrients (Panesar et al., 2007) and has relatively high- lactose content $-4.6-5.2 \%$ (Bergeman, 2003). Whey UF also is a cheap and valuable source of raw material. Besides lactose (35-50 g/L) it contains trace elements: 3-11 mg iron, 1-3 mg copper, 30-33 mg zinc, and $0.5-0.8 \mathrm{mg}$ manganese per $100 \mathrm{~g}$ of the dry matter, as well as vitamins: $80 \mathrm{mg}$ vitamin A, 5-6 mg thiamin, 5-10 $\mathrm{mg}$ pyridoxin, $15-20 \mathrm{mg}$ riboflavin, 50-60 $\mathrm{mg}$ calcium pantothenate, $0.1-0.3 \mathrm{mg}$ biotin, $0.02-0.05 \mathrm{mg}$ cobalamin and 20-40 mg vitamin C per $100 \mathrm{~g}$ of the dry matter. Therefore, whey and permeates can be used as a substrate for many microbial fermentations (Moulin, Galzy, 1984). A perspective way to use whey is the production of organic acidbased products. Lactose can be fermented by the Propionibacterium (Prb) into propionic (PA) and acetic acids as their main fermentation products, and nowadays due to the problems associated with increased oil prices and the benefits of eco-friendly production, biological PA biosynthesis emerges as a competitor to chemical synthesis (Ammar, Philippidis, 2021; Gonzalez-Garcia et al., 2017; Alonso et al., 2015; Vidra, Nemeth, 2018). Propionic acid is generally regarded as safe (GRAS) and can be applied as a preservative in animal feed, grains, and human food (Wang et al., 2015). PA has recently found applications also in the cosmetic, precursor for plastics, and

Copyright $\odot 2021$ The Authors. Published by Vytautas Magnus University. This is an open-access article distributed under the terms of the Creative Commons Attribution License (CC BY 4.0), which permits unrestricted use, distribution, and reproduction in any medium, provided the original author and source are credited. 
pharmaceutical industries (Gonzalez-Garcia et al, 2017). However, because of the low PA yield, caused partly by strong end-product inhibition, low productivity, and product purity, bio-based PA is limited and more expensive than its chemical synthesis (Wang et al., 2015; Vidra, Nemeth, 2018). This research was focused on whey UF fermentation by genetically unmodified (wild) organisms. We chose five classical Prb strains which are attributed to the dairy Prb subclass. The optimal temperature for Prb growth is around $28-30^{\circ} \mathrm{C}$ (Piwowarek et al., 2018; Vorobjeva, 1999), however, for energy-saving purposes the aim of the current research was to study the organic acid and biomass production of the chosen Prb at the room temperature $\left(22 \pm 0.5^{\circ} \mathrm{C}\right)$.

\section{MATERIALS AND METHODS}

Microorganisms were obtained from the Leibniz Institute DSMZ culture collection (German Collection of Microorganisms and Cell Cultures, GmbH). Following strains were used: DSM 20273 Acidipropionibacterium acidipropionici (Propionibacterium arabinosum) = A; DSM 20272 Acidipropionibacterium acidipropionici (Propionibacterium pentosaceum $)=$ B; DSM 4902 Prb. freudenreichii subsp. shermanii = E; DSM 20535 Acidipropionibacterium jensenii = J; DSM 20276 Acidipropionibacterium thoenii $=\mathrm{T}$. Original lyophilized cultures were propagated in $\mathrm{Na}$ lactate broth for 1 day at $30 \pm 0.5{ }^{\circ} \mathrm{C}$, then streaked on sodium agar plates and incubated anaerobically for 14 days at $30 \pm 0.5^{\circ} \mathrm{C}$ in anaerostat, using an anhydrous, anaerobic gas generator, Oxoid AN0035 bags. The cultures were subcultured three times prior to inoculation. One colony of each strain was transferred from the sodium lactate agar plate into a Falcon tube containing $50 \mathrm{~mL}$ of fresh medium and incubated for 3 days at $30 \pm 0.5^{\circ} \mathrm{C}$. The medium was composed of $63.77 \mathrm{~g} \mathrm{~L}^{-1}$ lactose monohydrate, $6.06 \mathrm{~g} \mathrm{~L}^{-1}$ yeast extract (Biolife, Italy), and salts: diammonium phosphate $2 \mathrm{~g} \mathrm{~L}^{-1}$, potassium dihydrogen phosphate $1 \mathrm{~g} \mathrm{~L}^{-1}$, magnesium sulfate heptahydrate $0.01 \mathrm{~g} \mathrm{~L}^{-1}$, calcium chloride hexahydrate $0.01 \mathrm{~g} \mathrm{~L}^{-1}$, cobaltous chloride hexahydrate $0.01 \mathrm{~g} \mathrm{~L}^{-1}$, ferrous sulfate heptahydrate $0.005 \mathrm{~g} \mathrm{~L}^{-1}$ and manganese sulfate monohydrate $0.0025 \mathrm{~g} \mathrm{~L}^{-1}$. The preculture was harvested by centrifugation (10 min at $\left.6000 \mathrm{rpm}\right)$ and washed twice with the sterile saline solution $\left(9 \mathrm{~g} \mathrm{~L}^{-1} \mathrm{NaCl}\right)$.

Fermentation media. Whey UF (lactose content $46 \mathrm{~g} \mathrm{~L}^{-1}$ ) was used as a sole fermentation media and substrate. Whey UF produced from mixed (acid and sweet) whey was obtained from the dairy company "Smiltenes Piens" JSC and inoculated with each of the 5 Prb strains. The cells were inoculated with a final biomass concentration to be approx. OD600 0.042. Blank samples without added bacteria were studied as a negative control (O).

Fermentation was performed in the $500 \mathrm{~mL}$ glass flasks sealed with sterile cotton plugs and covered with $\mathrm{Al}$ foil to avoid media evaporation. Flasks were then placed at $22 \pm 0.5^{\circ} \mathrm{C}$ room temperature for 26 days. The flasks were not shaken except for gentle agitation at the time of sampling.

Sample collection and storage. Samples were harvested at different time points aseptically, by carefully mixing the content of the flasks beforehand. Samples for organic acid content analyses were poured into the smaller sealable tubes and kept at $-18^{\circ} \mathrm{C}$ temperature until further analysis.

Analytical methods: pH was measured by a pH meter Jenway 3520 (Barloworld Scientific Ltd., Staffordshire, UK).

Biomass growth was monitored as OD measurements at $590 \mathrm{~nm}$ using spectrophotometer Jenway 6705 (Barloworld Scientific Ltd., Staffordshire, UK).

The content of propionic, lactic, and acetic acids was determined by HPLC. Samples were pretreated according to the method of Le Lay et al. (2016) with modifications: fermentation broth samples were centrifuged 20 min at $4^{\circ} \mathrm{C}$ and $15000 \mathrm{rpm}$, then $0.5 \mathrm{~mL}$ of the supernatant were mixed with $1 \mathrm{~mL}$ of $0.02 \mathrm{n} \mathrm{H}_{2} \mathrm{SO}_{4}$ to decrease the pH of the samples below 2.5 that ensures the dominance of undissociated forms of volatile fatty acids (Alkaya et al., 2009). Then samples were vortexed for $20 \mathrm{~s}$ and frozen for at least $2 \mathrm{~h}$ for protein precipitation in $-18 \pm 1{ }^{\circ} \mathrm{C}$ temperature. Before analysis samples were melted and $0.5 \mathrm{~mL}$ of the buffer solution was added; then samples were centrifuged (Centurion Scientific K241R PrO-Research) at $4{ }^{\circ} \mathrm{C} 15000 \mathrm{rpm}$ for $20 \mathrm{~min}$. Before HPLC analysis by Prominence system (Shimadzu LC-20) with DAD SPD-M20A detector and Nucleosil 100-5 C18 column (Macherey-Nagel), the supernatants were filtered through $0.45 \mu \mathrm{m}$ pore-sized nylon filters. HPLC mobile phase with isocratic elution was buffer solution containing 14.36 $\mathrm{g} \mathrm{L}^{-1}$ potassium dihydrogen phosphate and $20 \mathrm{~mL}$ acetonitrile acidified with ortho-phosphoric acid to $\mathrm{pH} 2.8$. The volume of the injected sample was $10 \mu \mathrm{L}$, flow rate $1.0 \mathrm{~mL} \mathrm{~min}^{-1}$ at $+25^{\circ} \mathrm{C}$. The injected sample volume was $10 \mu \mathrm{L}$. The acid peaks were identified by the retention times of the standards of each acid. To quantify, curves were drawn from the peak area against the concentration of standard $\left(\mathrm{g} \mathrm{L}^{-1}\right)$.

Statistical methods. All results are mean values from biological triplicates. Statistical analyses were made using the Microsoft Office program Excel. Data are presented as the mean \pm standard deviation (STDEV) unless explained otherwise. The hypotheses suggested were tested by Student's t-test; factors were considered significant if $\mathrm{p}<0.05$.

\section{RESULTS}

As a result of acidogenic activity, media total acidity, expressed as $\mathrm{pH}$ value, of the samples with added Prb gradually decreased from the initial $\mathrm{pH} 6.40$ to around $\mathrm{pH} 4.74$ on day 26 (Fig. 1). The most rapid decrease in pH occurred during the first 3 days. The slow decrease of the $\mathrm{pH}$ in the remaining fermentation period indicates a decline in the metabolic activity of microflora due to the end-product inhibition. 


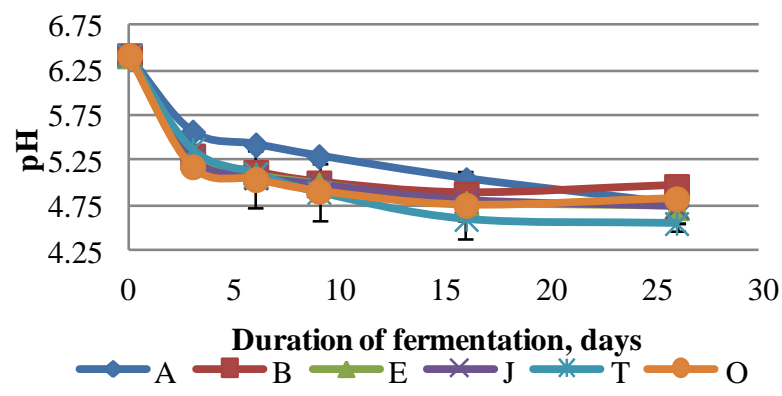

Figure 1. Changes of the $\mathrm{pH}$ during UF fermentation by different Prb strains (AVER \pm SEM)

The decrease of the $\mathrm{pH}$ in blank samples $(\mathrm{O})$ is most likely related to the activity of the background microflora (mainly lactic acid bacteria). The rapid accumulation of lactic acid during the first 6 days is most likely due to the presence of lactic acid bacteria (Fig. 2c). Lactic acid was already in the raw material, and it was $2.2 \mathrm{~g} \mathrm{~L}^{-1}$. Kinetics of the propionic, acetic, and lactic acids content in fermentation media is shown in Figure 2. Regarding all fermentation period, the increase in PA content in all Prb samples was gradual (Fig. 2a), while the largest quantity of the acetic acid increased relatively rapidly - during the first 6 days (Fig. 2b). That can be associated with the metabolic activity of Prb and of the background microflora, e.g., heterofermentative lactic acid bacteria (Panesar et al., 2007). Similarly, during the first 6 days, the accumulation of lactic acid peaked, see Fig. 2c. However, lactic acid was consumed later (after the $6^{\text {th }}$ day of fermentation) by Prb. Indeed, it is known, that Prb metabolize lactic acid and convert it into propionate, acetate, and $\mathrm{CO}_{2}\left(\mathrm{Johns}_{\mathrm{N}}, 1951\right.$; Wang et al., 2015).

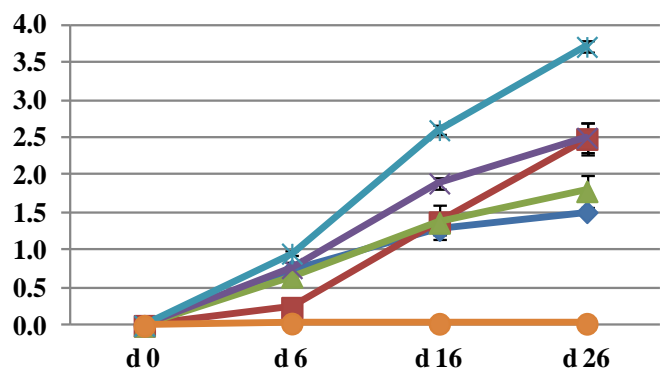

a. Propionic acid

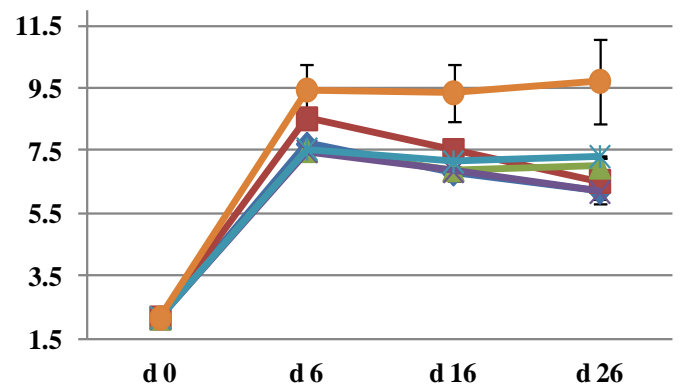

c. Lactic acid

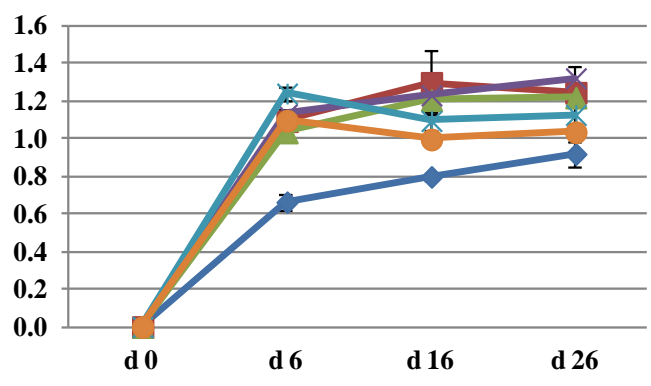

b. Acetic acid

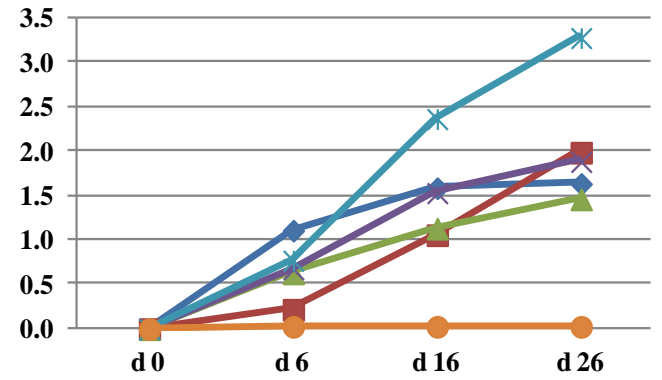

d. Propionic/acetic acid ratio

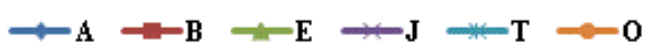

Figure $2 \mathrm{a}, \mathrm{b}, \mathrm{c}-$ content of propionic, acetic, and lactic acids $\left(\mathrm{g} \mathrm{L}^{-1}\right)$ in the UF permeate broth during fermentation (AVER \pm SEM), $\mathrm{d}-$ ratio of the contents of propionic and acetic acids

Regarding PA production, the highest concentration $-3.71 \mathrm{~g} \mathrm{~L}^{-1}-$ was reached by strain $\mathrm{T}$ on day 26 , followed by strains $\mathrm{J}$ and $\mathrm{B}\left(2.50\right.$ and $\left.2.49 \mathrm{~g} \mathrm{~L}^{-1}\right)$. The strain $\mathrm{T}$ was also the most effective PA producer within 6 and 16-day periods, followed by strain J. The less effective producers of PA within the 16-day period were strains A, B and E. Interestingly that initially, strain's B production of PA was the lowest, but after the 6-day period, its rate increased quite rapidly, 
surpassing even strains $\mathrm{A}$ and $\mathrm{E}$ at the end of the fermentation. Lactic acid was produced most rapidly and was the most abundant organic acid produced from whey UF.

The ratio of propionic and acetic acids contents (Rp/a) was calculated to understand which bacteria strain gives a higher proportion of the PA in the product. Higher concentrations of PA in various applications are considered an advantage, as the antimicrobial capacity of acetic acid against some microorganisms, e.g., fungi, bacteria, and molds, is weaker. In our study, the highest Rp/a was reached by the strain T which was also the most effective producer of PA (Fig. $2 \mathrm{~d})$. The general observation - Rp/a was gradually increased during the fermentation while at the same time the $\mathrm{pH}$ was decreased. A moderate negative linear correlation $(\mathrm{r}=0.71)$ between the $\mathrm{pH}$ value and the $\mathrm{Rp} / \mathrm{a}$ in fermentation samples with added Prb was seen in the current study (Fig. 3).

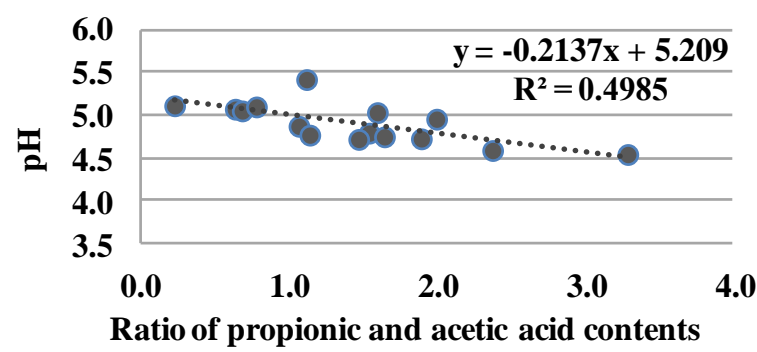

Figure 3. Correlation between the $\mathrm{pH}$ and $\mathrm{Rp} / \mathrm{a}$

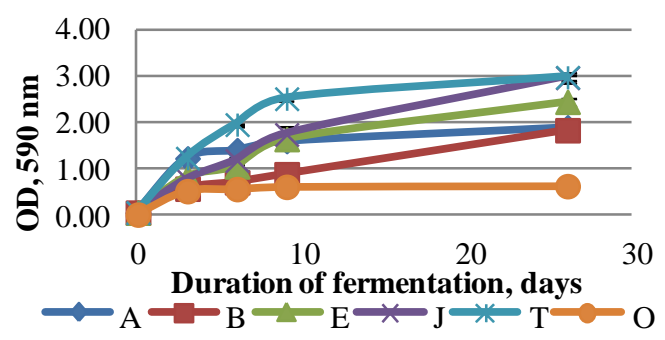

Figure 4. Changes of optical density during UF fermentation by different Prb strains (AVER \pm SEM)

Theoretically, propionate is the primary fermentation product of Prb (Piwowarek et al., 2018). Yet, lactic acid and part of the acetic acid produced in the current study may have been originated from the action of background microflora (heterofermentative lactic acid bacteria) as seen in blank samples, and therefore, the obtained results don't reflect the activity of Prb alone. In view of this, in the current study, Rp/a higher than 1 was reached after 6 days or in some samples (B and E) even after 16 days of fermentation, except for strain A, for which this value exceeded 1 already in 6 days.

The growths of bacterial biomass expressed as OD changes are shown in Fig. 4. The most pronounced increase in biomass during the 26-day period was observed in the samples with strains $\mathrm{T}$ and $\mathrm{J}$ (Fig.4). Considering the long total fermentation time, the growth of all strains was relatively slow, especially that of strain B. It must be concluded that similarly to acids, also biomass could be increasing at the expense of background microflora multiplication as seen from biomass increase in blank samples, and this result does not reflect the growth of Prb alone.

\section{CONCLUSIONS AND DISCUSSION}

Considering the choice of the most suitable Prb strains for acid production, it is important to reflect that the differences in the growth rate and acid production efficiency of various strains could be affected by the characteristics and nutritional requirements of individual strains. According to the review of Piwowarek et al. (2018), Propionibacterium from P.freudenreichii, P.jensenii, P.thoenii, and P.acidipropionici species (that also are represented in the current study) seem to be the most appropriate for the biotechnological production of propionic acid. According to the review of Gonzalez-Garcia et al. (2017), wild-type P. acidipropionici is more competitive in PA production than other native producers. In the current study, a distinct leader in PA production during the whole fermentation period was the strain T. The highest amount of PA produced by strain $\mathrm{T}$ within the 26-day period was $3.7 \pm 0.13 \mathrm{~g} \mathrm{~L}^{-1}$ and it was higher compared to $3.10 \mathrm{~g} \mathrm{~L}^{-1}$ reached by P. acidipropionici (strain ATCC 4875) as a steady-state concentration in the study of Morales et al. (2006) fermenting cheese whey UF (containing $50 \mathrm{~g} \mathrm{~L}^{-1}$ lactose with separately autoclaved and added trypticase buffer solution, containing yeast extract, trypticase, $\mathrm{K}_{2} \mathrm{HPO}_{4}$, and $\mathrm{MnSO}_{4}$ ) at $30^{\circ} \mathrm{C}$, in flasks flushed with nitrogen gas and agitated. P. acidipropionici strains A and B used in the current study were less efficient in PA production compared to Morales et al. (2006). In the current study strains A and B produced significantly lower $(\mathrm{p}<0.05)$ PA amounts $(1.51 \pm 0.02$ and $2.49 \pm 0.37 \mathrm{~g} \mathrm{~L}^{-1}$, respectively) as strain T, within the 26-day period. Looking to the same fermentation time (26d), the strains B and $\mathrm{J}$, as well Prb strains A and E were similar in the production of PA.

When choosing the most appropriate strain for PA production, it must be taken into consideration that the content of the PA produced depends on the duration of fermentation, and on proportions of other acids produced. As can be seen in the case with strain B, an individual strain initially can produce PA more slowly than others, but over time can be effective, that may be related to adaptation to environmental conditions and differential oxygen tolerance.

Numerous studies have focused on optimizing the fermentation process to improve propionate production. According to the other scientist's findings, one technique to improve the yield of acids is to restrict biomass production (Gonzalez-Garcia et al., 2017, Wang et al., 2013). This has been done by restricting nutrient availability (Scott et al., 2006) and by reducing the $\mathrm{pH}$ which also favors propionate production over acetate (Zhuge et al., 2013; Feng et al., 2010). The last observation is in line with our results, as a moderate negative linear correlation $(\mathrm{r}=0.71)$ between the $\mathrm{pH}$ value 
and the Rp/a in fermentation samples was found. Johns (1951) observed that the increase in $\mathrm{CO}_{2}$ tension has led to a higher Rp/a in the fermentation of glucose and concluded that this is a part of the explanation of the widely varying Rp/a reported in the literature because the experiments of other investigators have been carried out under varying conditions of $\mathrm{pH}$ and with different types of buffers. PA production can also be improved by extractive fermentation, using immobilized culture and/or genetically engineering methods, as well as other carbon sources. For example, immobilized mutant cells of $P$. acidipropionici (strain ATCC 4875) a fibrous-bed bioreactor with glucose as a carbon source produced a relatively very high amount of PA $-71.8 \mathrm{~g} \mathrm{~L}^{-1}$ (Suwannakham, Yang, 2005). Temperature can also play an important role in the acid formation and the growth rate of Prb. As found by Vorobjeva and Kozyreva (1967), then at $48{ }^{\circ} \mathrm{C}$ the growth is completely inhibited; at $37^{\circ} \mathrm{C}$ the growth rate is higher than at $30{ }^{\circ} \mathrm{C}$ or $22{ }^{\circ} \mathrm{C}$. However, Zodrow et al. (1967) observed that in long-term cultures the temperature optimum for growth was observed at $18{ }^{\circ} \mathrm{C}$. At this temperature, the largest accumulation of corrinoids was also found. But the maximal growth and vitamin accumulation were reached in 14 days, which is not economically sound for industrial production (Vorobjeva, 1999).

Regarding the other organic acids present in the product (fermentation broth), e.g., acetic acid, it is not always undesirable - together with other organic acids, it can provide a greater antimicrobial effect. Besides lowering the $\mathrm{pH}$, it is an excellent antimicrobial additive that has wide antibacterial and antifungal activities and can be regarded as a desirable metabolite to ensure general antimicrobial effects. Acetic acid has been used primarily to limit bacterial and yeast growth rather than mold growth, however also some molds are sensitive to this acidulant (Doores, 2002). Also, lactic acid presence can be regarded as desirable in fermentation products for its antimicrobial properties. The fast acid production and rapid increase in environmental acidity suppress the pathogenic microorganisms' activity (Widyastuti, Febrisiantosa, 2014). Lactic acid and lactates serve as a carbon source for Prb and even stimulate the acid production better than lactose as was observed in the studies of El-Hagarawy et al. (1957) in comparative experiments with five strains of P.shermanii in lactose and lactate media. The total acid production at two days in lactate media approximated that produced at eight days in lactose media.

Result also can be affected by other nutrient needs of individual strains (Vorobjeva, 1999). In the study of Gorret et.al (2001) the strain Prb. Acidipropionici DSM 4900 did not grow on the crude milk microfiltrate. As reviewed by Piwowarek et al. (2016) researchers have concluded that the Propionibacterium spp. belongs to the group of microorganisms with rich cultivation requirements. In addition to basic compounds essential for growth, a supply of specific growth factors is necessary: trace elements (iron, magnesium, cobalt, manganese, copper), vitamin B7 (biotin), vitamin B5 (pantothenic acid), and cysteine hydrochloride. Taking this into consideration, it would be better to avoid the pasteurization of the raw material to preserve the maximum amount of these valuable nutrients, necessary for the growth of bacteria, and to diminish the cost of additional nutrients as possible. However, there is an opposite argument why pasteurization or sterilization of the raw material (whey UF) should be done: the growth of PRB may be hampered by background microflora in unpasteurized raw material, e.g., lactic acid bacteria, their metabolites, or bacteriophage infection. As previously mentioned, UF used as the fermentation raw material could contain lactic acid bacteria. These microorganisms may have been originated from the starter cultures used in the production of cheese and cottage cheese or from the non-starter cultures - microorganisms of the raw milk microflora survived during milk pasteurization. According to the summary of Bautista (2014) although pasteurization destroys many spoilage bacteria and lessens the growth potential of others, heat resistant Lactococcus and Lactobacillus spp. can survive and grow. Also spores of Bacillus and Clostridium spp. can survive pasteurization temperatures. Species of Lactococcus, Lactobacillus, and Clostridium spp., Proteus spp., Pseudomonas, Flavobacterium, Bacillus spp., Micrococcus spp. also can survive pasteurization and cause spoilage of the UF. In addition, these microorganisms that survived during pasteurization can also get further to processed whey products. They can get into the UF if the filtration of whey does not provide $100 \%$ sterility to the permeate, or, most probably, can be secondary contamination, as the average filter pore size in ultrafiltration usually is $0.01-0.1 \mu \mathrm{m}$, maximally reaching $0.2-0.25 \mu \mathrm{m}$ (Alpma.com; Tunick, 2008), that is smaller size as the diameter of lactic acid bacteria. The presence of lactic acid bacteria in UF was observed also by Yang et al. (1995), but their presence did not seem to have severe adverse effects on propionic acid production. However, as reported by Alekseeva et al. (1983), nine out of 22 strains of lactic acid bacteria were antagonistic to Prb, with the greatest inhibition observed by $S$. lactis and $S$. diacetilactis. In the whey filtrate fermentation study by Vedamuthu et al. (1968), filtrates were obtained by filtering whey through $0.22 \mu \mathrm{m}$ pore-sized Millipore filters. Researchers observed that of the 56 Prb strains tested, 24 cultures comprising six species were inhibited by the whey filtrate. All studied whey samples exhibited inhibitory activity, regardless of the kind of cheese, source of the sample, or period of the year in which the whey was collected. The inhibitory activity also was stable at neutral $\mathrm{pH}$, but it was destroyed by heat treatment at $100{ }^{\circ} \mathrm{C}$ for ten minutes (Vedamuthu et al., 1968). These inhibitors may be bacteriocins or other antimicrobial substances produced by lactic acid bacteria, as well as bacteriophages infection. Individual resistance of various Prb strains to these factors can be different. Some Prb strains may be more resistant by naturally secreting mucus and thus protecting themselves from bacteriophage or other environmental factors (Vorobjeva, 1999). It can be concluded, that if the fermentation substrate - UF - is not pasteurized, the most suitable in terms of antimicrobial resistance strains of Prb should be used. In conclusion, when considering the suitability of different Prb strains for PA production, it is important to remind that the differences in the growth rate and acid production efficiency of various strains could be strongly affected by the characteristics and requirements of individual Prb strains and by the quality of the raw material, as well. 
The main findings of the current study are as follows:

1. As expected, all the strains were able to convert lactose into acid, however, with different efficiency, thus the production of PA by Prb is strain-dependent. The higher productivity of PA was observed in samples with strains $\mathrm{T}, \mathrm{J}$, and $\mathrm{B}$ in a 26-day period, however, it should be noted that also the strain $\mathrm{E}$ showed high efficiency in a shorter (6-day) period. The highest concentration of PA was produced by strain $\mathrm{T}$, and it reached $3.7 \pm 0.13 \mathrm{~g} \mathrm{~L}^{-1}$ within a 26-day period.

2. When choosing the most appropriate strain for PA production, it must be taken into consideration that the concentration of the PA produced depends on the duration of fermentation, and on proportions of other acids produced as well. An individual strain initially can produce PA more slowly than others, but over time can be effective, which may be related to adaptation to environmental conditions and differential oxygen tolerance.

3. The presence of background microflora in whey permeates most likely are lactic acid bacteria that can be either as natural microflora survived during milk pasteurization, inoculated starter cultures, or secondary contamination incurred, for example, during UF sampling or transportation

4. To preserve the maximum amount of whey valuable nutrients, necessary for the growth of bacteria, and to diminish the cost of additional nutrients, the substrate used in fermentation does not have to be pasteurized, provided that suitable strains of Prb bacteria are used and that the raw material is not contaminated with another undesirable microflora or bacteriophage infection.

5. Although the presence of lactic acid in the product is desirable since it serves as a carbon source for Prb and even can stimulate the PA production, the lactic acid bacteria or their metabolites in the raw material may affect the growth of Prb negatively, which would be worth exploring in future studies.

Acknowledgments. The research received funding from the ERDF Post-doctoral Research Support Program (project Nr.1.1.1.2/16/I/001) Research application "Processing of whey into value added products for food industry and agriculture" (Nr.1.1.1.2./VIAA/2/18/307). Thanks also to the cooperation partners - the dairy company "Smiltenes Piens" JSC for providing the fermentation raw material and Institute of Microbiology and Biotechnology of the University of Latvia for research cooperation and support.

\section{REFERENCES}

1. Alekseeva M.A., Anischenko I.P., Schlegel A.H., Ott E.F., Vorobjeva L.I. 1983. Improving the criteria of selection of propionibacteria for cheesemaking. In: Shlegel A.H. (ed) Nauchno Technichesky Progress, pp. 117-129. Barnaul.

2. Alkaya E., Kaptan S., Ozkan L., Uludag-Demirer S., Demirer G. N. 2009. Recovery of acids from anaerobic acidification broth by liquid-liquid extraction. Chemosphere, Vol. 77(8), pp.1137-42. https://doi.org/10.1016/j.chemosphere.2009.08.027

3. Alonso S., Rendueles M., Díaz M. 2015. Microbial production of specialty organic acids from renewable and waste materials (Review). Critical Reviews in Biotechnology, Vol. 35(4), pp. 497-513. https://doi.org/10.3109/07388551.2014.904269

4. Alpma.com: https://alpma.com/products/process-technology/membrane-filtration/ (Seen on 10.09.2021.)

5. Ammar E.M., Philippidis G.P. 2021. Fermentative production of propionic acid: prospects and limitations of microorganisms and substrates. Applied Microbiology and Biotechnology, Vol. 105, pp. 6199-6213. https://doi.org/10.1007/s00253-021-11499-1

6. Bargeman G. 2003. Separation technologies to produce dairy ingredients. In ed. by Gerrit Smit: Dairy processing. Improving quality, CRC Woodhead Publishing. https://doi.org/10.1201/9780203486207.ch17

7. Bautista D.A. 2014. Spoilage Problems | Problems Caused by Bacteria. In R.K., Robinson, C., Batt, P., Patel (eds): Encyclopedia of Food Microbiology (Second Edition), Academic Press. https://doi.org/10.1016/B978-0-12-384730-0.00314-1

8. Feng X.-H., Chen F., Xu H., Wu B., Yao J., Ying H.-J., Ouyang P.-K. 2010. Propionic acid fermentation by Propionibacterium freudenreichii CCTCC M207015 in a multi-point fibrous-bed bioreactor. Bioprocess and Biosystems Engineering, Vol. 33, pp. 1077-1085. https://doi.org/10.1007/s00449-010-0433-7

9. Gonzalez-Garcia R.A., McCubbin T., Navone L., Stowers C., Nielsen L.K., Marcellin E. 2017. Microbial propionic acid Production. Fermentation, Vol. 3, pp.1-20. https://doi.org/10.3390/fermentation3020021

10. Gorret, N., Maubois, J.L., Ghoul, M., Engasser, J.M. 2001. Exopolysaccharide production by Propionibacterium acidi-propionici on milk microfiltrate. J Appl Microbiol. 90(5), pp. 779-87. https://doi.org/10.1046/j.1365-2672.2001.01306.X

11. Le Lay, C.,Coton E., Le Blay G., Chobert J-M., Haertlé,T., Choiset Y., Van Long N., Meslet-Cladière L., Mounier J. 2016. Identification and quantification of antifungal compounds produced by lactic acid bacteria and propionibacteria. International Journal of Food Microbiology, Vol. 239, pp. 79-85. https://doi.org/10.1016/j.ijfoodmicro.2016.06.020

12. Morales J., Choi J.-S., Kim,D.-S. 2006. Production rate of propionic acid in fermentation of cheese whey with enzyme inhibitors. Environmental Progress, Vol. 25(3), pp. 228-234. https://doi.org/10.1002/ep.10153

13. Moulin G., Galzy P. 1984. Whey, a Potential Substrate for Biotechnology. Biotechnology and Genetic Engineering Reviews 1:1, pp. 347-374. https://doi.org/10.1080/02648725.1984.10647790

14. Panesar P.S., Kennedy J.F., Gandhi D.N., Bunko K. 2007. Bioutilisation of whey for lactic acid production. Food Chemistry, Vol. 105, Issue 1, pp. 1-14. https://doi.org/10.1016/j.foodchem.2007.03.035 
15. Piwowarek K., Lipińska E., Hać-Szymańczuk E. 2016. Possibility of using apple pomaces in the process of propionic-acetic fermentation. Electronic Journal of Biotechnology, Vol. 23, pp. 1-6. https://doi.org/10.1016/j.ejbt.2016.07.004

16. Piwowarek K., E., Hać-Szymańczuk E., Kieliszek M., Ścibisz I. 2018. Propionibacterium spp. - source of propionic acid, vitamin B12, and other metabolites important for the industry. Applied Microbiology and Biotechnology, Vol. 102, pp. 515-538. https://doi.org/10.1007/s00253-017-8616-7

17. Scott K.P., Martin J.C., Campbell G., Mayer C.D., Flint H.J. 2006.Whole-genome transcription profiling reveals genes upregulated by growth on fucose in the human gut bacterium "Roseburia. inulinivorans". Journal of Bacteriology, Vol. 188, pp. 4340-4349. https://doi.org/10.1128/JB.00137-06

18. Suwannakham S., Yang S. 2005. Enhanced propionic acid fermentation by Propionibacterium acidipropionici mutant obtained by adaptation in a fibrous-bed bioreactor. Bioengineering and Biotechnology, Vol. 91, pp. 325337. https://doi.org/10.1002/bit.20473

19. Tunick M. 2009. Whey Protein Production and Utilization: A Brief History. In Charles I., Onwulata Ph.D., Peter J. Huth (eds): Whey Processing, Functionality and Health Benefits; John Wiley \& Sons, Inc; 10.1002/9780813803845.ch1.

20. Vedamuthu E., Reinbold G., Hammond E. 1968. Inhibitory Activity of Acid and Rennet Whey on Propionibacteria. Journal of Dairy Science, Vol. 51, pp. 503-510. https://doi.org/10.3168/jds.S0022-0302(68)87019-5

21. Vidra A., Németh Á. 2018. Bio-produced propionic acid: A Review. Periodica Polytechnica Chemical Engineering, Vol. 62(1), pp. 57-67. https://doi.org/10.3311/PPch.10805

22. Vorobjeva I.L. 1999. Propionibacteria. Kluver Academic Publishers. https://doi.org/10.1007/978-94-017-2803-4

23. Vorobjeva L.I., Kozyreva L.F. 1967. Influence of temperature on vitamin B12 formation by Propionibacterium shermanii. Vestn Mosk Univ Biol, pp. 52-54.

24. Wang Z., Lin M., Wang L., Ammar E.M., Yang S.-T. 2014. Metabolic engineering of Propionibacterium freudenreichii subsp. shermanii for enhanced propionic acid fermentation: Effects of overexpressing three biotin-dependent carboxylases. Process Biochemistry, Vol. 50, pp.194-204. https://doi.org/10.1016/j.procbio.2014.11.012

25. Wang Z., Sun J., Zhang A., Yang S.T. 2013. Propionic acid fermentation. In S.T. Yang, H.A. El-Enshasy, N. Thongchul (eds): Bioprocessing Technologies in Biorefinery for Sustainable Production of Fuels, Chemicals, and Polymers; Wiley \& Sons: New York, pp. 331-350. https://doi.org/10.1002/9781118642047.ch18

26. Widyastuti Y.R., Febrisiantosa A. 2014. The Role of Lactic Acid Bacteria in Milk Fermentation. Food and Nutrition Sciences 5(4), pp. 435-442. https://doi.org/10.4236/fns.2014.54051

27. Yang S.T., Huang Y., Hong G. 1995. A novel recycle batch immobilized cell bioreactor for propionate production from whey lactose. Biotechnology and Bioengineering, Vol. 45(5), pp. 379-86. https://doi.org/10.1002/bit.260450502

28. Zhuge X., Liu L., Shin H.D., Chen R.R., Li J., Du, G., Chen J. 2013. Development of a Propionibacterium-Escherichia coli shuttle vector for metabolic engineering of Propionibacterium jensenii, an efficient producer of propionic acid. Applied and Environmental Microbiology, Vol. 79, pp. 4595-4602. https://doi.org/10.1128/AEM.00737-13

29. Zodrow K., Stefaniak O., Kaczmarek W. 1967. Influence of incubation temperature on the content of different corrinoids in the cells of Propionibacterium shermanii. Acta Microbiologica Polonica, Vol. 16, pp. 223-226. 